\title{
Analisis Vegetasi Gunung Merapi Menggunakan Quadrat Sampling Techniques
}

\author{
Ni Kadek Sri Ayu Wijayani ${ }^{1)}$, Yulia Nurvita ${ }^{1)}$, Lestari Widyaningsih ${ }^{1)}$, Vania Diah Salsabila \\ Kusumadyanta $^{1)}$, Ismi Nur Fajriyati A ${ }^{1)}$, Aulia Eka Rahayu ${ }^{1)}$ \\ Jurusan Pendidikan Biologi, Fakultas Matematika dan Ilmu Pengetahuan Alam, \\ Universitas Negeri Yogyakarta, \\ Jl. Colombo No.1, Caturtunggal, Depok, Sleman, Yogyakarta 55288 Indonesia \\ e-mail: ayuwijayani85@gmail.com
}

\begin{abstract}
Abstrak
Penelitian ini bertujuan untuk mengetahui keanekaragaman vegetasi dan dominansi pada areal penelitian di kawasan Gunung Merapi menggunakan teknik quadrat sampling setelah terjadi suksesi pasca 9 tahun erupsi. Data klimatik dan edafik yang diukur antara lain, suhu udara; suhu tanah; kelembaban udara; $\mathrm{pH}$ tanah di daerah Kinahrejo, Umbulharjo, Cangkringan, Sleman. Penelitian ini menggunakan 2 area plot yaitu plot 1 ( bantaran sungai bekas aliran lahar dingin), plot 2 (sungai bekas aliran lahar dingin). Teknik analisis data yang digunakan berupa analisis deskriptif. Berdasarkan hasil penelitian diperoleh tumbuhan dari 25 famili dan terdapat 36 spesies yang terbagi dalam 4 habitus. Vegetasi habitus Lichen, Parmelia saxalitas yang memiliki rerata INP tertinggi dengan jumlah 154,9509\% yang ada di plot 2, Habitus herba dengan indeks nilai tertinggi adalah Cynodon dactylon 158,5050\%. Indeks nilai penting tertinggi habitus semak adalah tumbuhan kelas Poaceae $64,6450 \%$ pada plot 1, berjumlah 6 koloni. Indeks penting tertinggi habitus tegakan yaitu Tamarindus indica 124,3808 \% yang berada di plot 1 .
\end{abstract}

Kata kunci-Dominansi, Keanekaragaman, Merapi, Quadrat Sampling Techniques, Vegetasi.

\begin{abstract}
This research aims to determine the diversity of vegetation and dominance in the research area in the Mount Merapi area using a quadrat sampling technique after a succession after 9 years of eruption. Climatic and edaphic data measured include air temperature; soil temperature; humidity; Soil $\mathrm{pH}$ in the area of Kinahrejo, Umbulharjo, Cangkringan, Sleman. This research uses 2 plot areas, namely plot 1 (riverbanks of cold lava flow), plot 2 (river of cold lava flow). The data analysis technique used is descriptive analysis. Based on the research results obtained by plants from 25 families and there are 36 species that are divided into 4 habitus. Lichen habitus vegetation, Parmelia saxalitas which had the highest INP rate with $154.9509 \%$ in plot 2, herbaceous herbals with value index the highest is Cynodon dactylon $158.5050 \%$. The highest importance index of shrub habitus was 64,6450\% Poaceae grade plants in plot 1, totaling 6 colonies. The highest important index of stand habitus is Tamarindus indica $124.3808 \%$ which is in plot 1 .
\end{abstract}

Keywords: Domination, Diversity, Merapi, Quadrat Sampling Techniques, Vegetation.

\section{PENDAhUluaN}

Menurut Maharadatunkamsi, et al., (2016) menyatakan Indonesia yang terletak di daerah tropis sebagai salah satu negara yang memiliki mega biodiversitas berupa keanekaragaman jenis tumbuhan dan hewan yang sangat tinggi. Kawasan gunung umumnya menunjukkan tingkat keanekaragaman vegetasi yang tinggi. Kerapatan vegetasi yang tinggi dapat menunjukkan dominasi atau penguasaan spesies di suatu area yang artinya spesies tersebut memiliki peran dalam mengontrol area tersebut (Brewer, 1994).

Erupsi Gunung Merapi tahun 2010 menunjukkan bahwa erupsi telah menyebabkan kerusakan yang sangat parah. Gangguan vulkanik seperti terjangan awan panas pada erupsi Gunung Me- 
rapi tahun 2010 telah mengakibatkan kebakaran hutan dan membentuk lahan terbuka. Lahan terbuka tersebut kemudian menjadi tempat terjadinya suksesi primer yang merupakan bagian proses ekologi gunung berapi aktif (Steenis,2006). Lereng selatan Gunung Merapi yang sebelumnya berubah menjadi lahan terbuka akibat terjangan awan panas akan ditumbuhi vegetasi hasil suksesi primer dan atau suksesi sekunder. Perubahan jenis vegetasi saat suksesi terjadi secara berangsurangsur dan melalui beberapa tahap dari komunitas tumbuhan sederhana sampai klimaks (Mukhtar, 2012). Vegetasi tersebut akan menginvasi lokasi yang sebelumnya terdampak erupsi untuk selanjutnya bisa ditumbuhi oleh jenis vegetasi yang lain (Indriyanto, 2006). Vegetasi yang dapat menunjukkan dominansi atau penguasaan spesies di suatu area dapat dikatakan memiliki peran dalam mengontrol area tersebut.

\section{METODE PENELITIAN}

Teknik sampling quadrat adalah sebuah teknik pendataan vegetasi menggunakan petak dengan ukuran dan jumlah tertentu. Penggunaan petak tunggal menunjukkan komunitas vegetasi dengan sifat homogen. Kusmana C. (1997) mengungkapkan petak contoh dapat ditentukan secara acak atau beraturan sesuai dengan prinsip teknik sampling. Sungai bekas aliran lahar dingin kemungkinan mengalami suksesi primer, hal ini ditunjukan dengan banyaknya material erupsi Gunung Merapi.

Penelitian dilakukan pada hari Jumat,11 Oktober 2019 hingga 22 November 2019. Daerah pengamatan analisis vegetasi dilakukan di daerah Kinahrejo, Umbulharjo, Cangkringan,Sleman dengan titik koordinat plot $1 \mathrm{~S}^{\circ} 7^{\circ} 34^{\prime} 54,4^{\prime \prime} \mathrm{E} 110^{\circ} 26$

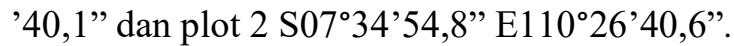

Alat yang digunakan pada penelitian ini yaitu: patok, tali raffia, meteran Panjang, gunting, kertas label, alat tulis, alat dokumentasi, hygrometer, thermometer udara, anemometer, soil tester, dan luxmeter.

Tahap persiapan: menentukan area studi dan menentukan batas-batasnya, menentukan areal yang paling representatif (dalam satu plot terdapat banyak jenis tumbuhan), alat dan organisasi team, penstratifikasian dan penarikan contoh serta penyiapan rencana kerja disertai peta kerja. Pada tahap ini dilakukan kegiatan: menentukan areal paling representatif, alat pengukuran; dokumentasi; dan tulis, menentukan luas minimum plot meliputi: membuat plot sebesar $2 \times 2$ meter pada areal yang dianggap paling representatif dan memulai identifikasi dan diteruskan hingga jumlah komulatif spesies tidak mengalami pertumbuhan.

Pasca penentuan luas minimum plot: membuat grafik luas minimum plot, menentukan luas minimum plot yang akan dibuat kembali untuk menentukan jumlah minimum plot meliputi: membuat plot sebesar hasil dari perhitungan grafik luas minimum plot yaitu 7x7 meter secara acak namun masih dalam area studi, penentuan plot selalu dimulai dari yang paling representatif hingga jumlah komulatif spesies yang teridentifikasi tidak bertambah lagi.

Pasca penentuan jumlah minimum plot: membuat grafik jumlah minimum plot, menentukan jumlah minimum plot sesuai perhitungan grafik yaitu 2 plot, membuat plot dengan luas minimum plot yang telah ditentukan yaitu $7 \times 7$ meter berjumlah 2 plot, melakukan identifikasi pada setiap plot

Analisis data: pengambilan sampel, identifikasi, inventarisasi, pengukuran klimatik dan edafik, dan penentuan koordinat pada setiap plot. Semua data yang telah diperoleh dikumpulkan secara sistematis dan disajikan secara informatif.

\section{HASIL DAN PEMBAHASAN}

Tabel 1. Indeks Nilai Penting Tertinggi dan Terendah Habitus di

\begin{tabular}{|c|c|c|c|c|}
\hline \multirow{3}{*}{ Habitus } & \multicolumn{2}{|c|}{ Stasiun 4} & \multicolumn{2}{|c|}{ 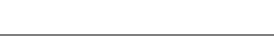 } \\
\hline & \multicolumn{2}{|c|}{$\begin{array}{c}\text { Indeks Nilai Penting } \\
\text { Tertinggi }\end{array}$} & \multicolumn{2}{|c|}{$\begin{array}{c}\text { Indeks Nilai Penting } \\
\text { Terendah }\end{array}$} \\
\hline & $\begin{array}{l}\text { Nama } \\
\text { tumbuhan }\end{array}$ & $\begin{array}{c}\text { Presentas } \\
\text { e }\end{array}$ & $\begin{array}{l}\text { Nama } \\
\text { tumbuhan }\end{array}$ & $\begin{array}{c}\text { Presentas } \\
\text { e }\end{array}$ \\
\hline Lichen & $\begin{array}{l}\text { Parmelia } \\
\text { saxalitas }\end{array}$ & $154,95 \%$ & $\begin{array}{l}\text { Salix alba } \\
\text { L. }\end{array}$ & $48,73 \%$ \\
\hline Herba & $\begin{array}{l}\text { Cynodon } \\
\text { dactylon }\end{array}$ & $158,51 \%$ & $\begin{array}{c}\text { Sorgum } \\
\text { halepense }\end{array}$ & $21,83 \%$ \\
\hline Semak & $\begin{array}{c}\text { kelas } \\
\text { Poaceae }\end{array}$ & $64,65 \%$ & $\begin{array}{l}\text { Agrimoni } \\
a \\
\text { eupatoria } \\
\text { L. }\end{array}$ & $5,23 \%$ \\
\hline $\begin{array}{c}\text { Tegaka } \\
\text { n }\end{array}$ & $\frac{\text { Tamarindu }}{\underline{\text { indica }}}$ & $124,38 \%$ & $\frac{\text { Psidum }}{\text { guajava }}$ & $33,69 \%$ \\
\hline $\begin{array}{l}\text { Semua } \\
\text { vegetasi }\end{array}$ & $\begin{array}{c}\text { Agrimonia } \\
\text { eupatoria } \\
\text { L. }\end{array}$ & $3,4174 \%$ & $\begin{array}{c}\text { Kelas } \\
\text { Poaceae }\end{array}$ & $\begin{array}{c}37,3786 \\
\%\end{array}$ \\
\hline
\end{tabular}

Observasi di lereng selatan gunung merapi didapat data bahwa vegetasinya masih sangat beragam. Vegetasi yang ditemukan sebanyak 25 famili dari 36 spesies yang terbagi menjadi 4 habitus yaitu lichen, herba, semak dan tegakan. Tumbuhan yang ditemukan termasuk dalam 
famili Acanthaceae, Amaranthaceae, Apocynaceae, Asteraceae, Cannabaceae, Caprifoliaceae, Chyatheaceae, Cornaceae, Cyperaceae, Dennstaedtiaceae, Dicranaceae, Dryopteridaceae, Fabaceae, Melastomataceae, Myrtaceae, Oxalidaceae, Parmeliaceae, Phytollaccaceae, Poaceae, Polygonaceae, Ranunculaceae, Rosaceae, Salicaceae, Smilacaceae, VerbenaceaeAcanthaceae, Amaranthaceae, Apocynaceae, Asteraceae, Cannabaceae, Caprifoliaceae, Chyatheaceae, Cornaceae, Cyperaceae, Dennstaedtiaceae, Dicranaceae, Dryopteridaceae, Fabaceae, Melastomataceae, Myrtaceae, Oxalidaceae, Parmeliaceae, Phytollaccaceae, Poaceae, Polygonaceae, Ranunculaceae, Rosaceae, Salicaceae, Smilacaceae, Verbenaceae. Tumbuhan pada habitus lichen ditemukan sebanyak 3 spesies dengan jumlah 28 koloni, tumbuhan pada habitus herba ditemukan 5 spesies dengan jumlah 59 individu dan atau koloni, tumbuhan pada habitus semak ditemukan paling banyak yaitu dengan 23 spesies sejumlah 119 individu dan atau koloni, dan tumbuhan pada habitus tegakan sebanyak 4 spesies sejumlah 12 individu. Tumbuhan pada habitus lichen yang jumlahnya paling banyak ditemukan yaitu Parmalia saxalitas, tumbuhan yang jumlahnya paling banyak ditemukan pada habitus herba yaitu spesies Cynodon dactylon, tumbuhan pada habitus semak yang jumlahnya ditemukan paling banyak yaitu tumbuhan Pteridium aquilinum, dan tumbuhan habitus tegakan yang jumlahnya paling banyak ditemukan dari spesies Anaphalis javanica. Data di analisis dari Indeks Nilai Penting (INP) tertinggi dan terendah dari setiap habitus. Habitus lichen, INP tertinggi Parmelia saxalitas dan INP terendah Salix alba L., habitus herba, INP tertinggi Cynodon dactylon dan INP terendah Sorgum halepense, tumbuhan habitus semak, INP tertinggi kelas Poaceae dan INP terendah Agrimonia eupatoria L. Terakhir tumbuhan habitus tegakan dengan INP tertinggi Tamarindus indica dan INP terendah yaitu Psidum guajava.

\section{A. Habitus Lichen}

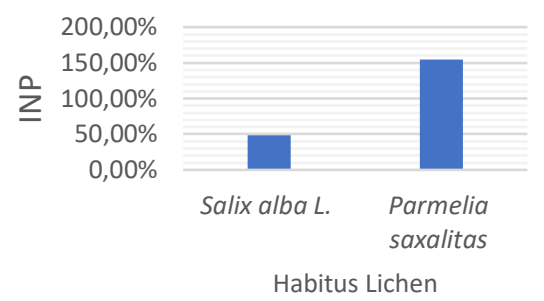

Gambar 1. Diagram INP tertinggi dan terendah Habitus Lichen.

Gambar 1 menunjukkan perbedaan INP vegetasi pada habitus lichen. $P$. saxalitas merupakan spesies dari habitus lichen dengan indeks nilai penting tertinggi $154,9509 \%$ yang berada pada plot 2. Memiliki morfologi bentuk talus memanjang, pipih, berwarna cokelat hingga kehitaman pada lingkar terdalam, pada lingkar terluar berwarna putih, ujung talus bertekstur sangat kering, dan biasa ditemukan pada batu-batu besar. Sedangkan S. alba L., memiliki indeks nilai penting terendah $48,7333 \%$ berada pada plot 1 dengan morfologi talus memanjang, seperti bercabang, berwarna hijau dan ditemukan pada tanah yang tidak terpapar matahari, menempel di bagian tanah dekat akar tumbuhan lainnya.

Perbedaan indeks nilai penting ini dapat disebabkan karena stasiun yang digunakan untuk penelitian terdiri dari dua lokasi dengan karakterisitik berbeda, yaitu dataran dan bekas sungai yang pernah dialiri lahar dingin letusan gunung Merapi. Plot 1 berada pada bagian dataran dan plot 2 pada bagian bekas sungai. $S$. alba L. memiliki indeks nilai penting terendah untuk habitus herba, karena pada plot 1 hanya ditemukan pada bagian yang berbentuk seperti lereng dan ditutupi banyak tumbuhan. Tumbuhan ini dapat bertahan pada substrat yang tidak terpapar matahari secara langsung, sedangkan pada plot 1 lebih banyak bagian yang cukup terkena paparan sinar matahari. Sehingga kondisi habitat dan faktor intensitas cahaya matahari yang kurang sesuai, menyebabkan $S$. alba L. memiliki indeks nilai penting terendah. $P$. saxalitas memiliki indeks nilai penting tertinggi, karena terdapat kesesuaian habitat pada plot 2 yang berupa batuan. Kondisi klimatik berupa intensitas cahaya dan kecepatan angin rupanya mampu menopang keberlangsungan hidup yang ditemukan. 


\section{B. Habitus Herba}

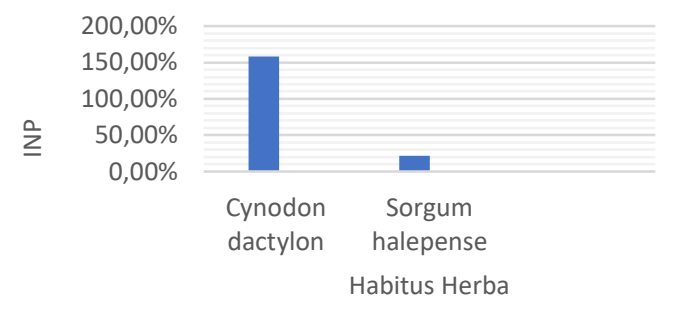

Gambar 2. Diagram INP tertinggi dan terendah Habitus Herba. Gambar 2 menunjukkan perbedaan tingkat INP vegetasi pada habitus herba. Spesies dari habitus herba dengan indeks nilai penting tertinggi adalah $C$. dactylon 158,5050\%. Memiliki morfologi helaian daun panjang seperti garis, tepi daun kasar, warna hijau muda, batang pipih, rongga batang kecil. Batang tumbuhan ini memiliki rongga untuk menyimpan air yang sangat cocok tempat hidupnya yang mana ditemukan pada plot 2 yang merupakan daerah sungai bekas aliran lahar dingin dan dipenuhi bebatuan. Karateristik batang yang dapat menyimpan air dan membuat dirinya mampu tumbuh dengan sangat baik ditanah kering nan bebatuan karena dapat menyimpan cadangan air dalam batangnya saat menerima banyak air pada musim hujan.

Indeks nilai penting terendah $S$. Halepense $21,8343 \%$ yang berada di plot 2 , memiliki morfologi sistem perakaran serabut muncul di bawah node di atas tanah, tulang daun lurus dan berwarna putih. Selain itu juga memiliki tingkat toleransi yang tinggi terhadap kekeringan (House, 1985). S. halepense memiliki sistem perakaran serabut, menyebabkan kurang berkembang di plot 2 yang lebih banyak bebatuan. Akibat kondisi tanah yang tidak begitu basah dan teksturnya agak kering, akar tumbuhan menjadi sulit untuk tumbuh menyebar dan menyerap air akibat banyaknya bebatuan pada area plot 2 , meskipun $S$. halepense memiliki tingkat toleransi yang tinggi terhadap kekeringan.

\section{Habitus Semak}

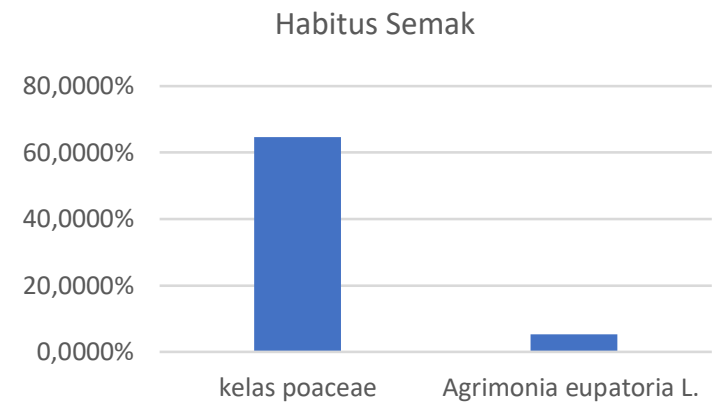

Gambar 3. Diagram INP tertinggi dan terendah Habitus Semak.

Gambar 3 menunjukkan perbedaan tingkat INP vegetasi habitus semak. INP tertinggi pada habitus semak merupakan tumbuhan kelas Poaceae, yaitu 64,6450\%. Tumbuhan ini memiliki batang beruas dengan bagian dalam berongga, ruas-ruasnya sering tumbuh akar, memiliki daun tunggal dengan posisi tersebar berseling, bentuk daun bulat memanjang atau lanset/pita dengan tulang daun sejajar. Menurut Sastrapradja, S (1980) suku rumput-rumputan atau Poaceae merupakan salah satu suku tumbuhan berbunga terpenting, baik dari segi botani maupun pertanian,. Tumbuhan ini mempunyai ciri tumbuh berumpun dan jarang soliter (Slamet,J.S, 1994). Poaceae dapat tumbuh baik di plot 1 dengan sistem perakaran serabut sehingga dapat menyebar dengan baik dan menyerap air lebih mudah dengan keadaan tanah yang tidak terlalu kering dan diperkirakan hanya terkena awan panas sehingga kondisi tanahnya tidak begitu kering. Selain itu tumbuhan kelas ini dapat berkembang pada substrat tanah meskipun dalam kondisi kering sekalipun, dengan karakteristiknya ini, kondisi tanah area plot 1 yang cukup kering tidak menjadi hambatan yang besar bagi keberlangsungan hidupnya.

Indeks nilai penting terendah A. Eupatoria L., yaitu $5,2291 \%$ berada pada di plot 1 dengan morfologi batang lurus, memiliki ram-but kasar menutupi seluruh tanaman, daunnya menyirip, di bagian atas berwarna hijau gelap dan beludru, hijau muda di bawah, ditempatkan bergantian, memiliki bunga berwarna kuning. Tumbuhan ini sulit tumbuh di lahan yang sangat basah sedangkan area plot 1 memiliki karakteristik tanah yang tidak basah justru cukup kering namun rendahnya INP ini dapat terjadi karena adanya kemampuan adaptasi yang kurang baik 
atau adanya persebaran tumbuhan yang tidak banyak pada area penelitian.

\section{Habitus Tegakan}

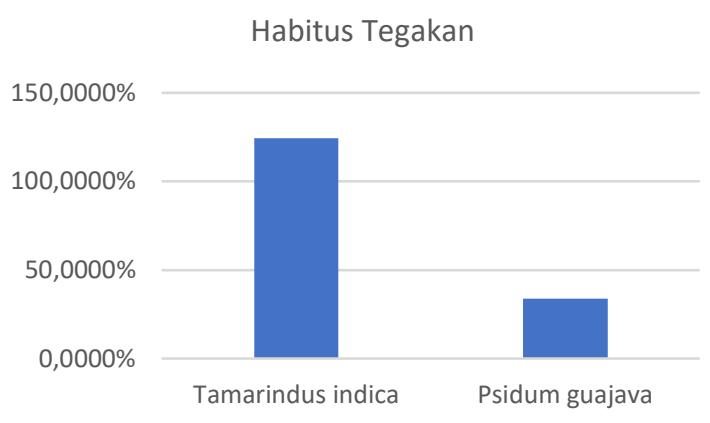

Gambar 4. Diagram INP tertinggi dan terendah Habitus Tegakan.

Gambar 4 menunjukkan perbedaan INP yang dimiliki vegetasi habitus tegakan. INP tertinggi habitus tegakan merupakan $T$. indica yaitu 124,3808 \% yang berada di plot 1 . Tumbuhan ini berwarna hijau sepanjang tahun, bagian atas sangat padat daun, banyak batang dan ranting, daunnya menyebar dengan luas dan melingkar, kulit batang kasar, bersisik, dan berwarna coklat keabuabuan, buahnya silindris sederhana atau melengkung dengan pinggir yang membulat. Daun tumbuhan ini yang tumbuh menyebar dan padat membuatnya dapat menerima banyak cahaya matahari dan melaksanakan proses fotosintesis cukup intens. Hal ini yang menyebabkan tumbuhan ini banyak ditemukan dan memiliki INP tertinggi.

Indeks nilai penting terendah $P$. guajava $33,6884 \%$ yang berlokasi di plot 1 . Tumbuhan ini memiliki batang berkayu, berwarna cokelat dan bercabang, memiliki daun tunggal berbentuk bulat telur dengan ujung tumpul, pangkalnya membulat dan tepi daun rata berhadapan, tulang daun menyirip berwarna hijau kekuningan (Parimin, 2005). Tumbuhan ini ditemukan masih dalam tahap pertumbuhan awal, kemungkinan yang terjadi adalah saat erupsi terjadi biji tumbuhan ini mengalami dormansi dalam tanah dan tumbuh setelah beberapa tahun namun persebaran yang tidak merata menyebabkan jumlah individu yang ditemukan tidak banyak. Perbedaan INP berdasarkan kondisi klimatis yang menunjukkan adanya pergerakan angin yang sangat keras pada habitus tegakan ini disebabkan karena $T$. indica tumbuh secara lambat, mampu bertahan terhadap angin yang kencang, dan berumur sangat pan- jang. Sedangkan $P$. guajava_memiliki ranting yang kecil sehingga mudah rusak oleh tiupan angin.

\section{KESIMPULAN}

Berdasarkan hasil penelitian dapat disimpulkan bahwa ditemukan 36 spesies dari 25 famili yang terbagi kedalam 4 vegetasi. Vegetasi lichen terdapat 3 spesies, dengan $P$. saxalitas memiliki INP tertinggi yaitu $154,9509 \%$ dan $S$. alba L., memiliki INP terendah yaitu $48,7333 \%$. Kemudian pada vegetasi herba terdapat 5 dengan spesies $C$. dactylon memiliki INP tertinggi yaitu $158,5050 \%$ dan $S$. halepense memiliki INP terendah, yaitu $21,8343 \%$. Vegetasi semak ter dapat 24 spesies, yang mana INP tertinggi pada tumbuhan kelas Poaceae yaitu $64,6450 \%$ dan INP terendah A. eupatoria L. yaitu 5,2291\%. Terakhir vegetasi tegakan ditemukan 4 spesies, dimana $T$. indica memiliki INP tertinggi, yaitu 124, 3808\%, sedangkan $P$. guajava memiliki INP terendah yaitu $33,6884 \%$.

\section{DAFTAR PUSTAKA}

Agung, S dan Wiwit. (2011). Hibah Penelitian Strategis Nasiona: Kajian Multi Bahaya, Keren-tanan, Risiko, Desain Tata Ruang Kawasan Rawan Bencana Merapi dan Implementasinya dalam Peningkatan Kapasitas dan Kesiapsiagaan Masyarakat Terhadap Bahaya Gunungapi. Laporan Penelitian. Yogyakarta: Universitas Gadjah Mada.

Brewer. (1994). The Science of Ecology. Sounders Collage Publishing. P: 41

House, L.R. (1985). Guide to sorghum Breeding, 2nd ed. India: ICRISAT.

Indriyanto. (2006). Ekologi Hutan. Jakarta: Bumi Aksara

Kusmana, C. (1997). Metode Survey Vegetasi. Bogor: IPB.

Maharadatunkamsi, T. Bagus Putra Prakarsa, dan Kurnianingsih. (2015). Struktur Komunitas Mamalia Di Cagar Alam Leuweung Sancang, Kabupaten Garut, Jawa Barat. Zoo Indonesia, 24(1), 51-59.

Mukhtar, A. S., et al. (2012). Keadaan Suksesi Tumbuhan pada Kawasan Bekas Tambang Batu Bara di Kalimantan Timur. Jurnal Pusat Litbang Konservasi dan Rehabilitasi. 
Parimin. (2005). Jambu Biji Budidaya dan Pemanfaatannya. Jakarta: Penebar swadaya. Sastrapradja, Setijati. (1980). Jenis Rumput Dataran Rendah. Bogor: Lembaga Biologi Nasional.
Slamet, J. S. (1994). Keseimbangan Lingku-ngan. Yogyakarta: Universitas Gadjah Mada. Steenis, V. 2006. Flora Cetakan Kelima. Jakarta: Pradya Paramita. 